\title{
Improving Experience Clues on a Journey for Better Customer Perceived Value
}

\author{
Duangthida HUSSADINTORN NA AYUTTHAYA and Pisut KOOMSAP ${ }^{1}$ \\ Industrial Systems Engineering, Asian Institute of Technology
}

\begin{abstract}
Value is in the eyes of customers, and business success relies on how customers perceive the value of what a company offers to them. Therefore, seeing value through the eyes of customers and properly design of customer experience journey have become important and grabbed the attention of practitioners and scholars in recent years. Failing to understand customer perception can cause damage and puts the company at risk of retaining a competitive advantage. However, current research has not yet provided a holistic and systematic structure in which experience clues and customer perceived channels are incorporated. Therefore, presented in this paper is a framework, based on the customer experience journey, to underline the role and the connection of experience clues and customer perceived channels on the customer experience journey. The proposed framework is illustrated through a real case study on broadband service for onboarding new customers. The framework is expected to provide practical value to a company and experience designers on improving their offerings to be more effective in order to achieve better customer perceived value.
\end{abstract}

Keywords. Customer Perceived Value, Experience Clues, Improvement, Customer Experience Journey

\section{Introduction}

Value is in the eyes of customers, and business success relies on how customers perceive the value of what a company offers to them. McDougall and Levesque found that value is another driver of customer satisfaction which, in turn, leads to customer future intentions [1]. According to this study, customer perceived value has been incorporated in models for designing and improving service quality in order to give a complete picture of the drivers of customer satisfaction [2-4]. Additionally, customer perceived value was investigated as a predictor of behavioral outcomes in the business market [5].

The relationship between customer experience and customer perceived value was revealed in 2007 by Gentile and colleagues [6]. They stated that experience is used as a channel to perceive product value. Incorporating this information in designing customer experiences may attain higher customer satisfaction and customer loyalty [7]. Recently, the overall experience that customers have, over time, with a company is defined as a customer journey [8]. A pain point-free journey is when customer satisfaction is retained in every single touch point along the entire journey. This concept is known as customer journey mapping (CJM). It is a well-known customer-oriented technique originated in the 1960s [9], and its applications have been seen in various fields of research [10]. There has been a growing research body on the further development of this concept, for

\footnotetext{
${ }^{1}$ Corresponding Author, Email: pisut@ait.asia.
} 
example, incorporation of CJM and service assembly concept [11], and embedding memorable experience to customer journey [12].

Customer journey consists of three stages: pre-purchase, purchase, and postpurchase. The middle stage, where customers make a decision and proceed their purchase, is viewed as a crucial stage for companies. Their interests have been centering on shopping experience [13], environments [14], and experience clues [15,16]. In-store designs and decorations, displays, sounds, performance, and behavior of staff are examples of experience clues that influence customer perception [16]. Different clues play different roles on the perception [15]. Some clues aim to meet customer expectation, and others are for exceeding the expectation.

Accordingly, seeing value through the eyes of customers and properly design of customer experience journey have become important and grabbed the attention of practitioners and scholars in recent years. Failing to understand customer perception can cause damage and puts the company at risk of retaining a competitive advantage. However, only a few research has partially concerned of this viewpoint in designing products and services [7,17]. A holistic and systematic structure in which experience clues and customer perceived channels are incorporated has not yet been developed.

Therefore, this paper aims to make a contribution for a better understanding and underlining the role and the connection of experience clues and customer perceived channels on the customer experience journey. A real case study on broadband service for onboarding new customers is selected to illustrate the proposed framework. The result, based on currently planned activities, provides a guideline for the company to improve its service designs to be more effective in order to achieve better customer perceived value.

The next section provides a theoretical review on customer perceived value, customer experience journey and experience clues which are the foundation of this research. The proposed framework is exemplified on the third section followed by the illustration on the mentioned case study. The conclusion is drawn in the last section.

\section{Literature review}

\subsection{Customer perceived value}

Customer perceived value was defined by Zeithaml as the overall assessment of the utility of a product or service [18]. When the perceived value meets or exceeds the customer's expectation, the exchange of value between the company and the customer occurs (Figure 1). The proposed value is realized and, then, creates value in return for the company.

Experience plays an important role during value perception at different touch-points (pre-purchase, purchase, and post-purchase) in the product life cycle and can be described by experiential components conceptualization [19]. The first component was the sensorial component which consists of all five senses (sight, hearing, touch, taste, and smell) that can stimulate aesthetic pleasure, excitement, satisfaction and a sense of beauty. The second one was the emotional component involving moods, feeling, and emotions that can stimulate an effective relationship with a company, its brand as well as products. The third one was the cognitive component related to customer thinking or conscious mental process. The remaining two components were the lifestyle component that reflects personal belief during the consumption stage of services and products. The 
pragmatic component has been introduced as the sixth component [6]. It focuses on usability and practical acts in product life-cycle stages. During perception process, these experiential components may be stimulated individually as pure experiential components or in a complex way due to the interrelations among them as mixed experiential components which are difficult to distinguish the influence of each individual.

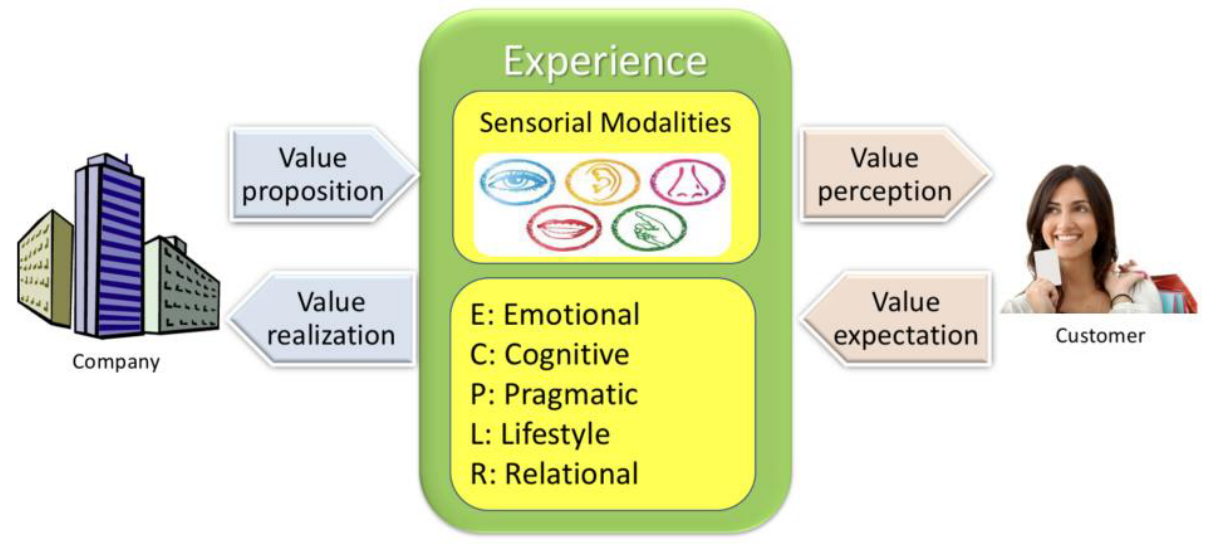

Figure 1. Value proposition framework (Modified from [6]).

Incorporating customer perceived value in designing customer experience resulted in strengthening customer satisfaction and customer loyalty [7]. It is found that customer perceived value can be reflected from a commitment and interest to involve with a product as depicted in commitment/involvement matrix (Figure 2). Customer commitment connects to two experiential components: the pragmatic component that is measured by frequent purchase/use and the cognitive component that is measured by complexity level. High levels of these components mean high commitment. Customer interest of involvement connects also to two experiential components: the emotional component that is measured by the degree of offering cost and lifestyle component that is measured by the degree of impact on self's image of the customers. High levels of these components also mean strong interest. When the levels of both customer involvement and commitment are low, the relational component can be identified as absent or superficial. According to the survey in Italy, McDonald's, H.C. Brand Bars, Pringles, and Nike were the examples of products in this group. When the level of customer involvement is low but commitment is high, the relational component can be identified also as absent or superficial. Gatorade, IKEA, and Playstation were examples. When the level of customer involvement is high and the commitment is low, the relational component can be identified as the collection. Swarovski and Swatch were examples of this group. Profound presents the highest level of relation that occurs when the levels of both customers involvement and commitment are high. For this group of products, the customers will not only use or consume but will also share their lifestyle with the others who have a similar interest. Harley-Davidson, iPod, and Smart were examples of this class. 


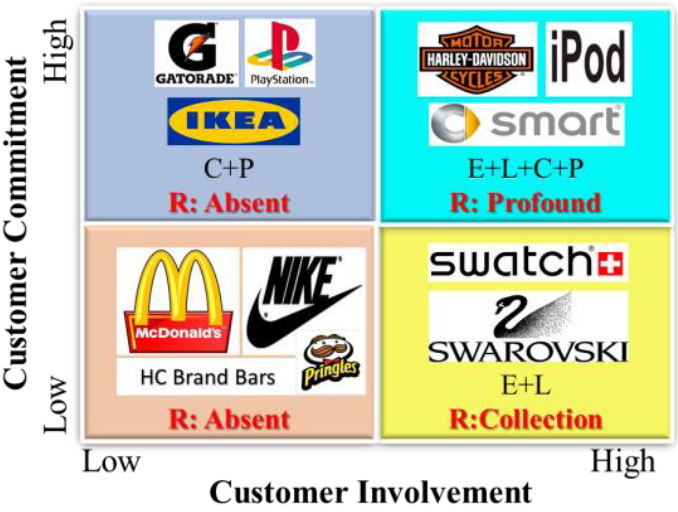

Figure 2. Commitment/Involvement matrix (Modified from [6]).

\subsection{Customer experience journey}

A journey with a company over time across multiple touchpoints is defined as customer experience [8]. The total customer experience is a dynamic process begins from prepurchase stage, continues to purchase stage, and finishes at post-purchase stage, as illustrated in Figure 3. This process is iterative. The past and future experiences are incorporated into this process. Information about past experiences contributes to the current experience as feedback. The current experiences also have an influence on future experience. In each stage, customers interact with different types of touchpoints - brand owned, partner owned, customer owned, and social/external - and have specific behaviors.

For the pre-purchase stage referring to entire experiences of customers before purchase, customers interact with the brand, category, and environment before making their purchase. At this stage, their behaviors are needed recognition, search, and consideration. Moving to the purchase stage, it receives very huge attention from practitioners. Researchers in the areas of retailing and consumer products research pay attention to 'shopping experience' [13]. Another group pays their interest in improving the environment and atmospherics [14]. Customer behaviors in this stage are choice, ordering, and payment. For the post-purchase stage, the critical touchpoint is at the product itself. Customer behaviors in this last stage are usage and consumption, postpurchase encouragement, and service requests.

During each stage of the journey, different touch points have a different level of strength/importance according to the nature of the offerings in the journey, and the journey itself. Brand-owned touch points are under the control of the company such as media (advertising, website, loyalty program, etc.), product, services, packaging, sale force, etc. Partner-owned touch points are under the joint control between the company and its partners. Customer-owned touch points are out of control from the company and the partners. They are customer actions contributed to the overall experience such as their thinking process and desires during the pre-purchase stage. For the social/external touch points are somethings surrounding customers and are not under the control of the company and the partners. Example are review sites, social media, peer influences, environments, and other customers. 


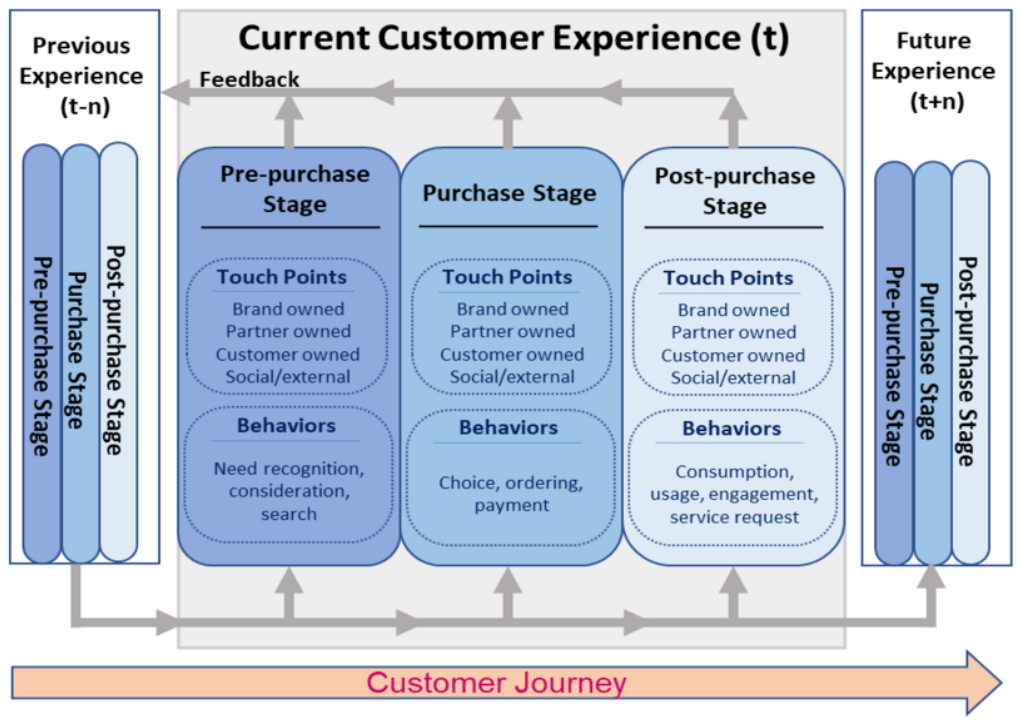

Figure 3. Process model for customer journey and experience (Modified from [8]).

\subsection{Experience clues}

Experience clues, according to Berry and Carbone, are something that perceivable or sensible and recognized by its presence [16]. The clues can be categorized into two categories. The first one is the functional clue, which interpreted by rational thought, concerns the reliability and functionality of the product/service. The second one consisting of mechanic and humanic clues, both are interpreted by emotion. Mechanic clues are emitted by service environments, for instance, displays, furnishings, sounds, smells, lighting. Humanic clues are emitted by service providers, for example, choice of words, a tone of voice, body language, neatness, and appropriate dress. The integration of all the clues stimulates the customers' total experience. However, Zaltman stated that the total experience results from emotions than rational thinking [20]. As Figure 4 shows, the three clues play different roles to form customer perception [15]. Functional clues assist in meeting customer expectation. The other two are supplementary. Customers' first impression, expectation, and value creation can be influenced by mechanic clues. Humanic clues support exceeding customer expectation.

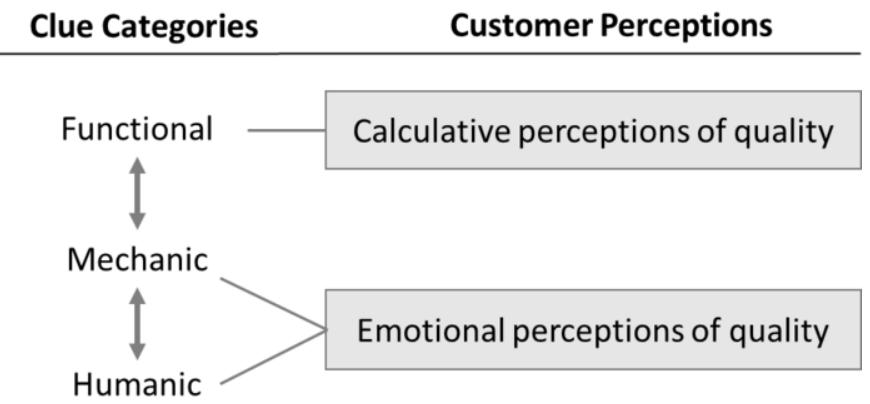

Figure 4. Clue influences on customer perceptions [15]. 


\section{Customer perceived value on customer experience journey: experience clues- driven design}

The economy has been progressing to the experience economy where a company's offerings cover products, services, and experiences [21]. In this experience era, the company intentionally uses its services as the stage, and goods as props, to engage customers to an experience journey. Customers gradually walk through the journey containing a set of activities which can be classified into three main stages: pre-purchase, purchase, and post-purchase, as illustrated in Figure 5. It is not unusual that customers perceive these activities differently. As mentioned earlier, the value is in the eyes of customers. The ways they are seeing the value of the offerings can be complicated and may be different from the company who designs the offerings. Furthermore, their perceptions of the same activity can also be different among themselves because of their different backgrounds, cultures, personal interests, perspectives, etc. Understanding customer perception process becomes, therefore, indispensable for the company to design the experience journey.

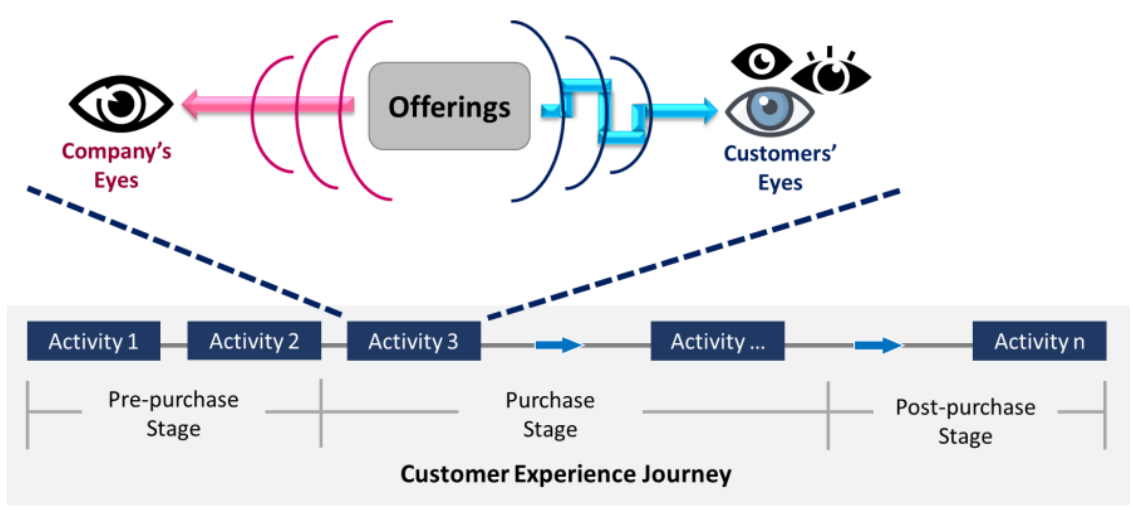

Figure 5. Customer perceived value on customer experience journey.

What is actually at a glance of customers on a journey is not an offering itself whether it is a product, service, or experience - but experience clues embedded into the offering, as illustrated in Figure 6. The experience clues are supplementary that fulfill the purpose of the activity and they can be categorized into three groups: humanic clue, mechanic clue, and functional clue. Humanic clue is the behaviors and performances of an operator/employee. The mechanic clue is an ambiance of an activity. These two types of experience clue may or may not be embedded into an offering. However, the functional clue is a must-have attribute for all activities as it is a capability that fulfills the purpose of the activity.

Therefore, in order to propose a perceivable customer experience journey to customers, the clues must be embedded in all activities in the journey. How the clues should be designed, in detail, is principally depending upon the ways customer perceive the value of the offerings. Customers perceive value from various sensorial modalities: sight, hearing, smell, taste, and touch. What they perceive from the five senses stimulates different directions of their experiential components. This information crucially contributes to designing experience clues for each activity. A well-designed clue is defined as being able to fulfill the purpose of the activity and, at the same time, fully 
meet or exceed the expectation of customers towards the activity. With a set of welldesigned clues on the experience journey, it retains and encourages customers to continue their journey with the company. However, an improper-designed clue can stimulate a negative perception which potentially leads customers to step out of the journey.

An example can be viewed in a restaurant. During a pre-consumption stage, customers look at the outside looks of the shop. If they see a long queue or if it is crowded, it implies that the shop must be the popular one and the foods might be tasty. This information is the functional clue that encourages customers to step in and observe the menu. When a waiter greets customers and invites them to an appropriate table, customers perceive a warm welcome from the humanic clue stimulating a sense of pleasure to them. Customers, then, would love to have a menu and make an order. When the customers open the menu and see some illustrated pictures and the clear explanation on each dish, they are perceiving the mechanic clues. The clues provide choices to customers and encourage them to make an order.

All of the mentioned clues are not exist, unless the shop uses a glass wall to present inside-shop ambiance, trains the waiters, and properly designs the menu book. In case the waiter ignores the customers and being impolite, the customers may quit the shop and seek for the better restaurant. From this example, it is seen how the experience clues and customer perceived channels play their key roles in retaining customers in the experience journey.

In the next section, the process of experience clues-driven design for better customer perceived value on customer experience journey is presented through an illustration on a real case study on broadband service.

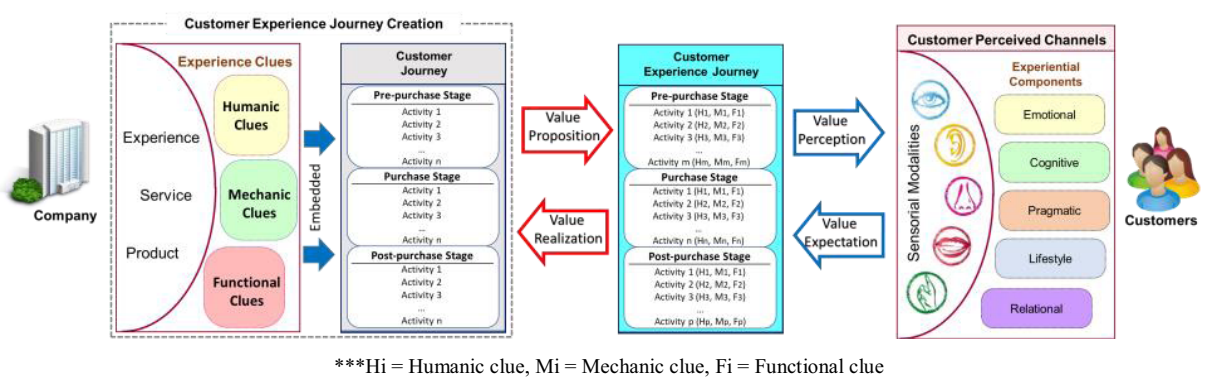

Figure 6. Customer perceived value framework on customer experience journey: experience clues-driven design.

\section{Illustration}

\subsection{Case study on mobile internet device}

Telenor ASA is one of the world's largest mobile telecommunications companies operating worldwide. The company provides several parallel channels to serve its customers such as retail stores, call centers, and websites. In the Scandinavian market, Telenor observed that there is a lack of fixed broadband infrastructure, especially in rural areas, resulting in an opportunity to launch a new product on a mobile internet device (MB) to this market. The company was interested in bringing and adopting the concept of customer journey analysis to detect potential weak points in the onboarding journey for new MB customers [22]. 
To start doing that, the MB planned journey was identified throughout examining of the service process, mystery shopping activities, and discussing with representatives from the call center. The scope of the journey was set from the point of purchase until one week after the installation. And this journey was designed for new customers only. This journey is challenging because the customers will interact with various offerings from different outsources via mediums such as call, email, and letter.

For this current research, its intention is centering at the development of the MB planned journey from the perspective of customer perception only. The contribution is going to answer how should the company design the detail of each activity for customers to be able to highly and effectively perceive the value of all offerings during walking through the journey. Identifying and eliminating the potential weak points are not including in this research.

The nine activities from the MB planned journey are presented in Table 1 with the customer behaviors for each stage of a journey which retrieved from the process model for customer journey and experience (Figure 3).

Table 1. List of activity [22] and customer behavior [8] for the MB planned journey.

\begin{tabular}{ccc}
\hline No. & Activity & Behavior \\
\hline $\mathrm{A}_{1}$ & Customer orders MB through the call center & choice, ordering, payment \\
\hline $\mathrm{A}_{2}$ & Receives e-mail confirming the purchase & \\
$\mathrm{A}_{3}$ & Receives e-mail confirming dispatch of hardware & \\
$\mathrm{A}_{4}$ & Receives welcome letter with information & \\
$\mathrm{A}_{5}$ & Receives letter containing the SIM card & usage, encouragement, \\
$\mathrm{A}_{6}$ & Receives letter containing the PIN code & service requests \\
$\mathrm{A}_{7}$ & Receives package containing modem and installation guide & \\
$\mathrm{A}_{8}$ & Receives invoice for hardware & \\
$\mathrm{A}_{9}$ & Customer installs the MB system & \\
\hline
\end{tabular}

\subsection{Result}

This section presents the exploitation of the proposed framework to the MB planned journey, as illustrated in Table 2. The nine activities are categorized into four groups according to their similarities. The process of experience clues-driven design begins with analyzing the possibility to embed the three clues into each group of activities. To design the clues for a particular activity, the characteristic of the clues and customer behaviors towards the activity is analyzed and matched with the feasibility and potential to stimulate a set of experiential components. An example can be seen through the designing of the humanic clues for activity $\mathrm{A}_{1}$ as follows.

- Emotional components: greeting, caring, a tone of voice

- Cognitive and lifestyle components: providing choice and related information according to personal needs and interests

- Pragmatic components: providing insights and related information, guiding and directing a customer to the completion of the process very quickly

The identified information is combined to form the design of the humanic clues for A1, as illustrated in Table 2. Customers will be perceiving this set of clues during talking with an operator; therefore, hearing is identified in the column of sensorial modalities. 
Table 2. Experience clues-driven design table for the MB planned journey.

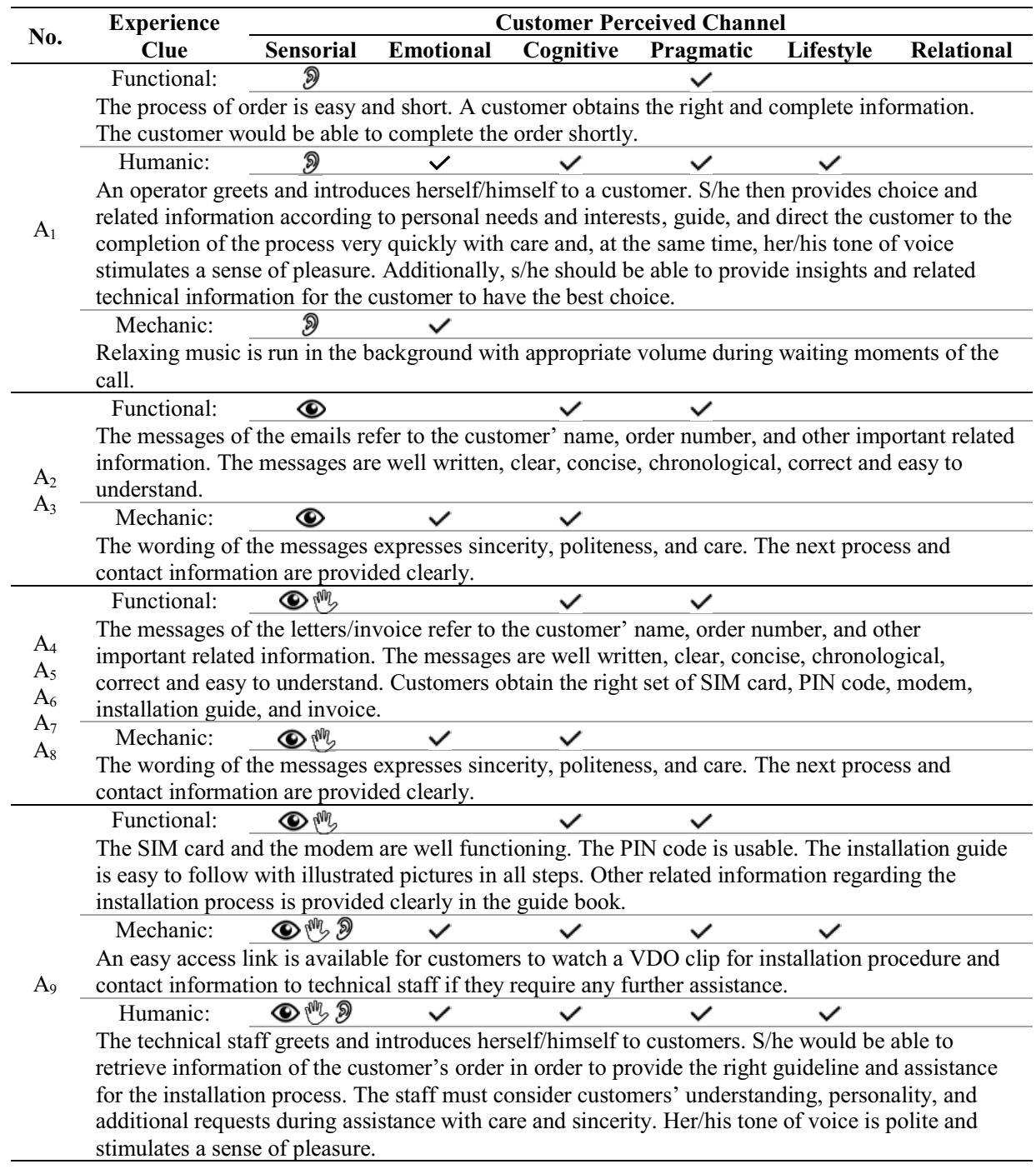

\section{Conclusion}

The experience clues-driven design for better customer perceived value on customer experience journey framework has been developed. The framework has been illustrated on the MB planned journey designing for onboarding new customers of Telenor ASA company. The results provide a guideline for designing experience clues for the activities in the journey to be more perceivable and be able to fulfill the expectations of customers effectively. The guideline, in another perspective, can be viewed as a set of proactive design solutions to limit the occurrence of service failure and customer dissatisfaction. However, the guideline should be implemented in practice to get feedback for further development and improvement. 


\section{References}

[1] G. H. McDougall, and T. Levesque, Customer satisfaction with services: putting perceived value into the equation, Journal of services marketing, vol. 14(5), 2000, pp. 392-410.

[2] C. F. Chen, Investigating structural relationships between service quality, perceived value, satisfaction, and behavioral intentions for air passengers: Evidence from Taiwan, Transportation Research Part A: Policy and Practice, vol. 42(4), 2008, pp. 709-717.

[3] Y. F. Kuo, C. M. Wu, and W. J. Deng, The relationships among service quality, perceived value, customer satisfac-tion, and post-purchase intention in mobile value-added services, Computers in human behavior, vol. 25(4), 2009, pp. 887-896.

[4] C. F. Chen, and F. S. Chen, Experience quality, per-ceived value, satisfaction and behavioral intentions for her-itage tourists, Tourism management, vol. 31(1), 2010, pp. 29-35.

[5] A. Eggert, and W. Ulaga, Customer perceived value: a substitute for satisfaction in business markets?, Journal of Business \& industrial marketing, vol. 17(2/3), 2002, pp. 107-118.

[6] C. Gentile, N. Spiller, and G. Noci, How to sustain the customer experience: An overview of experience compo-nents that co-create value with the customer, European Management Journal, vol. 25(5), 2007, pp. 395-410.

[7] D. Hussadintorn Na Ayutthaya, and P. Koomsap, Incorporating Customer Perceived Value in Designing Customer Experience, In: The International Conference on Sustainable Smart Manufacturing (S2M), Lisbon, Portugal, 2016.

[8] K. N. Lemon, and P. C. Verhoef, Understanding customer experience throughout the customer journey, Journal of marketing, vol. 80(6), 2016, pp. 69-96.

[9] A. Crosier, and A. Handford, Customer journey mapping as an advocacy tool for disabled people: a case study. Social Marketing Quarterly, vol. 18(1), 2012, pp. 67-76.

[10] A. Følstad, K. Kvale, and R. Halvorsrud, Customer journey measures-State of the art research and best practices, SINTEF Rapport A24488, 28 p. SINTEF, 2013.

[11] Q. Y. Li, C. H. Lee, C. H. Chen, Y. C. Lee, and F. Li, Dynamic enhancement for customer experience by incorporating customer experience journey map and service assembly concept, Advances in Transdisciplinary Engineering, Vol5: A Paradigm Shift, 2017, pp. 860-867.

[12] D. Hussadintorn Na Ayutthaya, and P. Koomsap, Embedding Memorable Experience to Customer Journey, In: Moon I., Lee G., Park J., Kiritsis D., von Cieminski G. (eds) Advances in Production Management Systems. Production Management for Data-Driven, Intelligent, Collaborative, and Sustainable Manufacturing. APMS 2018. IFIP Advances in Information and Communication Technology, vol. 535. Springer, Cham, 2018, pp. 222-229.

[13] C. Ofir, and I. Simonson, The effect of stating expectations on customer satisfaction and shopping experience, Journal of Marketing Research, vol. 44(1), 2007, pp. 164-174.

[14] L. L. Berry, L. P. Carbone, and S. H. Haeckel, Managing the total customer experience.(Essay), MIT Sloan management review, vol. 43(3), 2002, pp. 85-90.

[15] L. L. Berry, E. A. Wall, and L. P. Carbone, Service clues and customer assessment of the service experience: Lessons from marketing, Academy of Management Perspectives, vol. 20(2), 2006, pp. 43-57.

[16] L. L. Berry, and L. P. Carbone, Build loyalty through experience management, Quality progress, vol. 40(9), 2007, pp. 26.

[17] G. D. S. Ludden, and T. J. L. Van Rompay, How does it feel? Exploring touch on different levels of product experience, Journal of Engineering Design, vol. 26(4-6), 2015, pp. 157-168.

[18] V. A. Zeithaml, Consumer perceptions of price, quality, and value: a means-end model and synthesis of evidence. Journal of marketing, vol. 52(3), 1988, pp. 2-22.

[19] B. Schmitt, Experiential marketing, Journal of marketing management, vol. 15(1-3), 1999, pp. 53-67.

[20] G. Zaltman, Lighting Up the Shadows. Presentation, Procter \& Gamble's Future Forces Conference, Cincinnati, Ohio, 1997.

[21] B. J. Pine, and J. H. Gilmore, Welcome to the experience economy, Harvard business review, vol. 76, 1998, pp. 97-105.

[22] R. Halvorsrud, K. Kvale, and A. Følstad, Improving service quality through customer journey analysis, Journal of service theory and practice, vol. 26(6), 2016, pp. 840-867. 